\title{
Orígenes de las escuelas agropecuarias en la provincia de Entre Ríos, Argentina (1896-1910)
}

\section{Janet Priscila Cian}

CONICET. Universidad Nacional de Entre Ríos, Universidad Autónoma de Entre Ríos, Argentina

janetcian@hotmail.com

Cita sugerida: Cian, J. P. (2018). Orígenes de las escuelas agropecuarias en la provincia de Entre Ríos, Argentina (1896-1910). Mundo Agrario, 19(42), e093. https://doi.org/10.24215/15155994e093

Recibido: 03 mayo 2018 - Aceptado: 27 julio 2018 - Publicado: 07 diciembre 2018

(c) (i) (2) (2) Esta obra está bajo licencia Creative Commons Atribución-NoComercial-CompartirIgual 4.0 Internacional

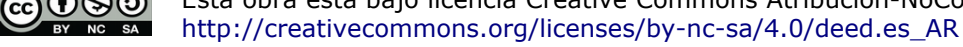




\section{Orígenes de las escuelas agropecuarias en la provincia de Entre Ríos, Argentina} (1896-1910)

The Roots of Agricultural Schools in Entre Rios, Argentina (1896-1910)

Janet Priscila Cian

CONICET. Universidad Nacional de Entre Rios,

Universidad Autónoma de Entre Rios, Argentina

janetcian@hotmail.com

\section{Resumen:}

Este artículo reconstruyó el desarrollo institucional de escuelas agropecuarias de jurisdicción nacional y provincial en Entre Ríos (1896-1910). El propósito central fue presentar la intervención del Estado provincial mediante la organización de establecimientos agropecuarios para la capacitación de personal idóneo en estas actividades y con objetivos de transformación productiva. En la conclusión se acentuó que la articulación entre el sistema educativo y las necesidades productivas tuvo un mayor impulso hasta 1910, cuando este objetivo fue soslayado por las demandas de alfabetización de la población mediante la educación común.

Palabras Clave: Escuelas agropecuarias, Entre Ríos, Políticas educativas.

\section{Abstract:}

This paper reconstructed the institutional development of agricultural schools of national and provincial jurisdiction in Entre Ríos (1896-1910). The main purpose of this work was to present the intervention of the provincial State through the organization of agricultural establishments for the training of qualified personnel in this type of activities and with objectives of productive transformation of the territory. Using a qualitative perspective, I examined a corpus comprising diverse primary sources. As a conclusion, it is argued that the articulation between school system and production needs gained momentum until 1910, when this goal was overlooked given to population's literacy demands, therefore changing to regular education.

KEYWORDS: Agricultural schools, Entre Rios, Education policies.

\section{INTRODUCCIÓN}

Los estudios clásicos de historia de la educación han destacado la función política que asumió la organización del sistema educativo argentino, cuyo objetivo era asegurar la estabilidad y cohesión interna (Tedesco, 1986). Este propósito significaba una escasa conexión del sistema educativo con las demandas de la economía, lo cual no implicó la ausencia de proyectos alternativos o intentos de reforma para brindar una formación utilitaria vinculada con los requerimientos de la economía agroexportadora y una industrialización embrionaria.

Por consiguiente, el estudio histórico de la orientación productiva del sistema educativo ha sido un tema relativamente estudiado en Argentina, en particular la educación agrotécnica y la enseñanza primaria en las escuelas rurales, cuya producción historiográfica se ha desarrollado en los dos últimos decenios. En este lapso se realizaron investigaciones que constituyen aportes significativos para el estudio del subsistema de educación agropecuaria dependiente del Ministerio de Agricultura de la Nación (Gutiérrez, 2005, 2007a y 2007b; Ascolani, 2007; Plencovich, Costantini y Bocchicchio, 2009); estas investigaciones están referidas a las políticas nacionales y los desarrollos institucionales en la región pampeana, o en áreas de las llamadas economías regionales como es el caso de Mendoza (Rodríguez Vázquez, 2011, 2013 y 2014) y de Tucumán (Moyano, 2011).

El vínculo entre formación docente, educación primaria y conocimientos técnicos agrarios ha sido tratado en los últimos años. La evolución de las escuelas normales rurales, la capacitación de los agricultores y la orientación de la escolarización primaria rural también han sido objeto de investigaciones particulares, 
que abordaron los aspectos institucionales generales (Ascolani, 2007 y 2011; Gutiérrez, 2007; Brumat 2010; Mayer, 2014). El currículo de la educación primaria, las orientaciones pedagógicas y las experiencias innovadoras relacionadas con la enseñanza utilitaria rural han sido abordados más recientemente (Ascolani, 2015, 2017).

Este artículo ${ }^{1}$ se centró en la reconstrucción del desarrollo institucional de las escuelas agropecuarias ${ }^{2}$ instaladas en la provincia de Entre Ríos en el período comprendido entre 1896 y 1910. La delimitación de este recorte temporal se basó en la constatación de una temprana intervención del Estado provincial como agente promotor de una formación agropecuaria escolarizada, orientada a satisfacer necesidades productivas de la región, en el marco de una política provincial más amplia de fomento agropecuario y de expansión de la frontera agrícola. A su vez, dentro de este lapso, tuvo lugar un momento de consolidación y desarrollo de estas instituciones, durante el quinquenio 1903-1908, en general coincidente con la gobernación de Enrique Carbó, candidato electo del Partido Demócrata Nacional. El fin de esta etapa se vincula con la retracción del Estado en su papel de organizador de esta oferta de educación agropecuaria.

Las instituciones analizadas son: la Escuela Nacional de Agricultura y Ganadería "Las Delicias" y los establecimientos provinciales de Agricultura e Industrias Derivadas de Villa Urquiza, Normal Rural e Industrial "Juan Bautista Alberdi" -las tres ubicadas en el departamento Paraná---; la escuelas Agropecuaria "Justo José de Urquiza”, en el departamento Villaguay, Agropecuaria e Industrial "Tomás Espora” en Concordia y la Agropecuaria "9 de Julio", en Don Cristóbal, departamento Nogoyá (Fig ura 1). Dado que estas instituciones no han sido tratadas por la historiografía, se ha realizado una reconstrucción de sus pasos iniciales a partir de un corpus variado de fuentes: memorias de Gobierno, mensajes de gobernadores, leyes y decretos, boletines de Educación, informes de inspectores, memorias de la Dirección General de Enseñanza, memorias del Ministerio de Agricultura de la Nación, estadísticas oficiales, expedientes escolares de las jurisdicciones departamentales, archivos institucionales y periódicos de diversa extracción política.

La provincia de Entre Ríos, ubicada dentro la región litoral de la Argentina, experimentó durante la primera mitad del siglo XIX una expansión ganadera desarrollada con posterioridad a la crisis del orden colonial (Schmit, 2004; Hora, 2010), que se consolidó luego de la prolongada fase de enfrentamientos bélicos que se produjeron en el territorio. La agricultura tuvo, en cambio, un desarrollo marginal, ligada fundamentalmente al autoabastecimiento.

A mediados de siglo XIX, y siendo sede del gobierno de la Confederación Argentina, se promovieron los primeros intentos de colonización agrícola con población llegada del extranjero -inmigración suizo valesana, española, italiana y belga ${ }^{3}$-, que han sido caracterizadas como exponentes del modelo de organización autocentrado, destinado a satisfacer el autoconsumo (Djenderedjian, 2008).

Iniciada la segunda mitad del siglo XIX, el devenir del proceso colonizador entrerriano comenzó a evidenciar un retraso en el desarrollo económico en comparación a las provincias de la Pampa Húmeda, debido a diversos factores internos, entre ellos la escasa infraestructura para transporte, la conflictividad política, los cambios en la valorización de la tierra y la inexistencia de una frontera abierta a conquistar (Gallo, 1984; Schmit, 2004; Djenderedjian, 2008, Martirén, 2016).

La ley nacional № 817, de Colonización e Inmigración, sancionada en 1876, favoreció la llegada de otras colectividades: los alemanes del Volga e israelitas, en su mayoría provenientes de Rusia. Los primeros llegaron en 1878 y se instalaron en el Departamento Diamante, manteniendo inicialmente la organización aldeana imperante en el país donde habían permanecido durante casi un siglo (Popp y Dening, 1977). Los judíos arribaron en 1892, amparados por la Jewish Colonization Association ante las persecuciones que sufrían en países de Europa y Asia (Avni, 2005) y se instalaron principalmente en el departamento Villaguay, aunque también se fundaron colonias en Concepción del Uruguay y Colón. Para la élite dirigente provincial esta inmigración favorecería la transformación de prácticas productivas de la población local ${ }^{4}$ dando lugar al desarrollo de una agricultura moderna y más productiva (Barsky y Gelman, 2005). Sin embargo, a fines de siglo los datos estadísticos de la provincia contrastaban con las proyecciones dado que de un total de 931.292 
hectáreas destinadas a la labranza en 1896, solo se habían cultivado 390.150, mostrando un retroceso con respecto a períodos anteriores ${ }^{5}$.

La crisis agrícola acaecida entre 1896 y 1897 obligó al gobierno provincial de Salvador Macia a tomar medidas de socorro para los productores rurales y a institucionalizar su acción a través de la organización de la Sección de Agricultura dependiente del Ministerio de Gobierno, con la función de supervisar las colonias y establecer campos de experimentación de cultivos. Los funcionarios de gobierno y el periodismo comenzaron a explicar la crisis productiva atribuyéndola a las limitaciones culturales de los inmigrantes recién llegados y a su ineficacia productiva. La crisis del sector continuó durante la gobernación de Pascual Echague, interregno donde la provincia experimentó déficit presupuestario y un creciente malestar de la población por la disposición de medidas tributarias regresivas y prácticas políticas caracterizadas por el nepotismo.

A partir de 1903 el gobernador Enrique Carbó buscó dar un nuevo estímulo a la colonización oficial ${ }^{6}$ mediante la organización de seis nuevas colonias efectuadas a partir de la liquidación de propiedades del Banco Provincial, la modernización agropecuaria y la estabilidad de los colonos en el campo con diversas medidas, entre ellas la creación de escuelas agropecuarias para formar personal idóneo en estas tareas y respondiendo a las necesidades productivas regionales.

Como antecedente, la provincia había promovido algunas iniciativas de educación para el trabajo; entre ellas incluir la orientación agrícola en la educación primaria, y una escuela agrícola rural en 1887 -Ley $\mathrm{N}^{\circ}$ 1366, del 18 de octubre de 1887- y una normal rural -en 1894- a localizare en el departamento Villaguay. Aunque estos proyectos no prosperaron.

Recién a partir 1903, con una coyuntura económica favorable, el gobierno provincial concretó la fundación de instituciones educativas para la formación agropecuaria. Con esto cumplía con las intenciones expresadas en la nueva Constitución Provincial, instituida ese año, en reemplazo de la Constitución de 1883, que implicó importantes cambios en la instrucción pública, ya que estableció dos tipos de enseñanza: común -primaria o secundaria- y especial. Enfatizaba en la enseñanza agropecuaria y creaba para las jóvenes una "Escuela Técnica del Hogar”. La reforma constitucional de 1903 convirtió el Consejo General de Educación en Dirección General de Enseñanza ${ }^{7}$ hasta 1909 y estableció que las rentas destinadas a la educación no podrían ser menores al veinte por ciento de las rentas generales de la provincia. La Ley de Educación $\mathrm{N}^{\circ} 1904$-de 1905- confirmó la educación especial, fijando que “...la enseñanza común se refiere a asignaturas que todas las personas deben saber y la enseñanza especial se refiere asignaturas que solamente a ciertas personas interesa aprender, dándole habilidad en alguna profesión" ${ }^{8}$.

Entre los argumentos pedagógicos que fundamentaban la creación de estas instituciones estaba el diagnóstico ligado a la maduración psicológica del educando en la pubertad, en la que emergían aptitudes del individuo que la educación debía atender brindando una especialización de los conocimientos. Por otro lado, frente a la polémica suscitada tres años antes a nivel nacional con motivo de la fracasada reforma proyectada por el ministro Osvaldo Magnasco, que proponía una mayor relación entre la educación primaria y secundaria con las necesidades productivas, las escuelas especiales eran vistas como un punto intermedio entre las instituciones secundarias y los establecimientos de artes y oficios (Vega, 1905; Dussel, 1997).

El gobierno provincial tenía previsto crear una institución de este tipo en cada uno de los catorce departamentos existentes en esa etapa ${ }^{9}$.

Sin embargo, sólo se pudieron organizar cuatro dependientes de la Dirección General de Enseñanza, y el gobierno nacional hizo lo propio al crear un establecimiento agrícola y ganadero. 
Figura 1. Mapa actual de la provincia de Entre Ríos con la ubicación de las escuelas agropecuarias. En 1904 el territorio estaba organizado en 14 departamentos
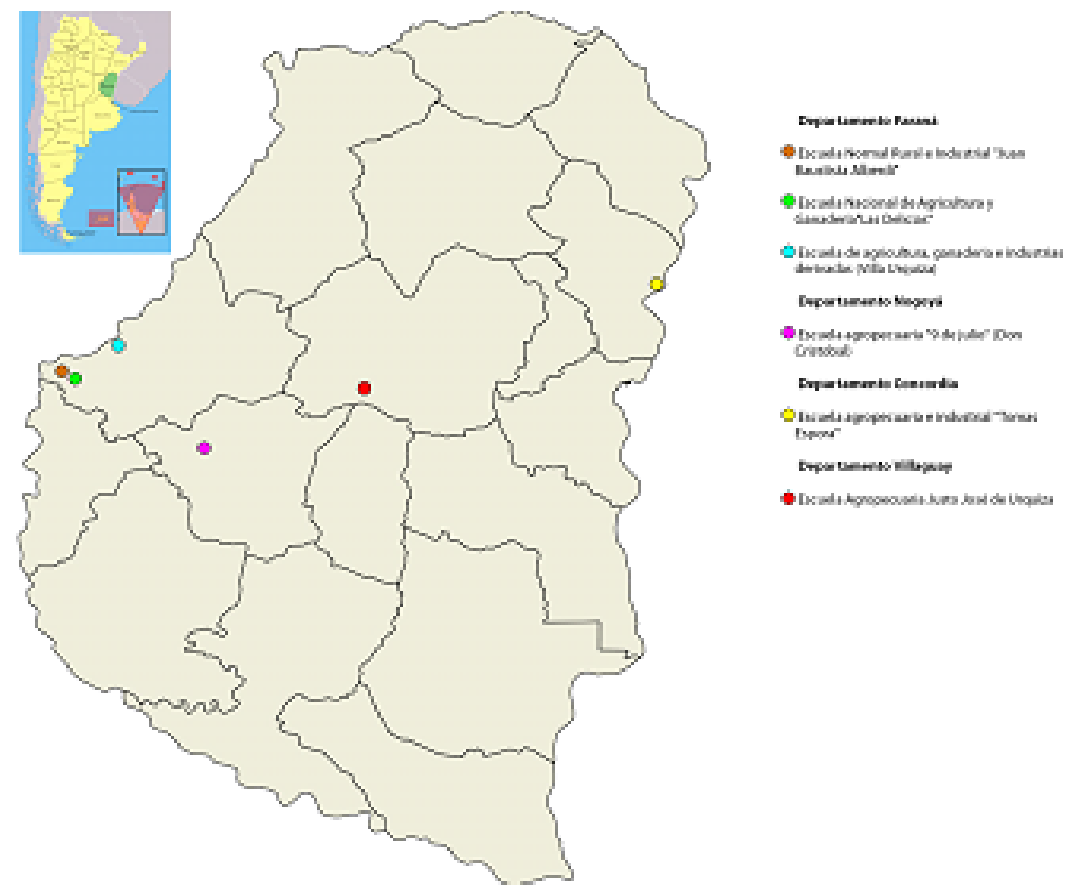

2. Escuela de Agricultura, Ganadería e Industrias Derivadas de Villa Urquiza, UN ANTECEDENTE

Fundada inicialmente en una zona de quintas de la ciudad de Paraná en 1896, durante la gobernación de Salvador Macia, la resolución de organización de este establecimiento elemental de agricultura incluía un reglamento interno que establecía diversas pautas: los alumnos podrían ser internos o externos, y para su ingreso se requería una edad mínima de 15 años, certificación de buena conducta, salud e instrucción elemental. El plan de estudio comprendía las materias de las escuelas comunes y materias teóricas y prácticas relacionadas con la agricultura ${ }^{10}$. En 1898 fue reubicada ${ }^{11}$ en un área de 61 hectáreas en Villa Urquiza ${ }^{12}$, una localidad ubicada a $20 \mathrm{~km}$ de Paraná, debido a la conveniencia de instalarla en una zona de colonización agrícola. Entre los argumentos que justificaban la adquisición de esta propiedad y su traslado, se planteaba la necesidad de asegurar su desarrollo, por la utilidad que reportaría a la provincia en esa coyuntura de superación de la grave crisis productiva que atravesó en el bienio, en consonancia con otras medidas de promoción dictadas por el gobierno. La duración de los estudios era de tres años, se seguían los programas de la enseñanza primaria que se usaban en Francia -botánica, agronomía general, horticultura, agricultura, arboricultura, meteorología, climatología, geología, mineralogía, química agrícola, viticultura, apicultura, sericicultura-, y el título que se obtenía era de capataz agrónomo, expedido por el Consejo General de Educación. En ese momento inicial, contaba apenas con once estudiantes, becados por el gobierno provincial.

La organización interna de la escuela quedaba bajo la responsabilidad de un director que asumió funciones de maestro y para lo cual fue nombrado el ingeniero agrónomo Gastón de Cleves ${ }^{13}$, que asumía la tarea de enseñanza de todos los cursos y contaba con la ayuda de dos peones, cuyo sostenimiento fue fluctuante. ${ }^{14} \mathrm{Al}$ exceso de funciones del director y el escaso personal se sumaba la carencia de insumos básicos para poner en funcionamiento una institución sobre la cual el gobierno tenía amplias expectativas, vinculadas a las necesidades de la producción agrícola y ganadera. Situación que dio lugar a un intento de renuncia del director y, a causa de este malestar, en 1901, el gobernador decidió el traspaso institucional bajo la órbita del Ministerio de Gobierno, auxiliado por la Sección de Agricultura. Fue modificado el plan de estudios, mediante Ley $\mathrm{N}^{\circ}$ 1808, estableciéndose un ciclo de tres años, sin modificar los aspectos fundamentales del plan anterior, 
no obstante permitía la obtención del título de maestro rural cursando el cuarto año ${ }^{15}$. Con esta opción, egresaron tres maestros rurales que fueron nombrados como directores en escuelas de los departamentos Rosario del Tala, Gualeguay y La Paz.

Los cambios en la institución y el apoyo del gobierno en los dos años siguientes permitieron mejoras en la infraestructura, compra de insumos y aumento del número de becas, lo que posibilitó mayor cantidad de alumnos ingresantes, aspecto que era satisfactoriamente percibido por la prensa provincial ${ }^{16}$.

En 1904 fue decretada su transferencia desde el Ministerio de Gobierno a la Dirección General de Enseñanza Pública, cumpliendo con lo establecido por la nueva constitución provincial de 1903, que otorgó la dirección técnica, superintendencia, inspección y vigilancia de la enseñanza especial a este último $\operatorname{organismo~}^{17}$. El cambio de dependencia fortaleció la organización de las secciones de agricultura, ganadería, apicultura, sericicultura, avicultura, cremería y vitivinicultura, en las cuales se realizaban las prácticas de formación de los alumnos. La producción obtenida -vino, caña, grapa, miel, cebollines y maíz- era vendida y un porcentaje de las ganancias quedaba para la institución.

El reajuste de planes de estudio dio lugar a que, en 1905, la escuela tuviese tres años de enseñanza primaria, en la que se daban lecciones de lectura, escritura, aritmética, geografía, geometría, historia, mientras que al mismo tiempo se desarrollaba el programa de agricultura, ganadería e industrias rurales. La enseñanza estaba a cargo del director, un profesor, un maestro de enseñanza primaria, un maestro de enseñanza industrial, otro de arboricultura; un celador controlaba a los alumnos y el mantenimiento era realizado por cuatro peones, un cocinero y una lavandera. $\mathrm{Al}$ año siguiente el número de alumnos llegó a veinte becados, aunque no había pensionistas ni oyentes.

Luego del alejamiento del primer director, este cargo estuvo ocupado por el perito agrónomo Alberto Ferré (1906) y el Dr. Luis Goncebatt (1906-1907), posteriormente director de la normal rural. En 1908 se nombró a José Ferré, quien se venía desempeñando como maestro de la misma.

Los alumnos que concluían sus estudios ingresaban como aspirantes al magisterio rural. En 1908 los nueve egresados obtuvieron beca para continuar sus estudios en la normal rural "Juan Bautista Alberdi”.

\section{Escuela Agropecuaria “Justo José de Urquiza” de Villaguay: en el corazón de LAS COLONIAS}

En agosto de 1904 el gobierno provincial autorizó al Consejo Administrativo de la Enseñanza a adquirir una finca de 150 hectáreas cercana a la ciudad de Villaguay, departamento homónimo ${ }^{18}$ ubicado en la zona central de la provincia, con el objetivo de crear una escuela agropecuaria ${ }^{19}$. En el departamento Villaguay la Jewish Colonization Association, compañía del Barón Mauricio Hirsch, fue conformando un enorme latifundio -que en 1903 sumaba 69.821 hectáreas- con propósitos filantrópicos, destinado a desarrollar la colonización agrícola.

El gobierno dispuso en 1904, a través de la Ley No 1917, la expropiación -con compra- de tierras privadas en un área intermedia entre las jurisdicciones de Paraná y Concordia, que resultaba estratégica para instalación de este establecimiento agropecuario (Vega, 1905, p. 96).

La creación de esta institución se relacionaba con el plan de enseñanza especial impulsado a partir de 1903, pero debió sortear una campaña periodística en su contra, que defendía la prioridad de crear un estableciendo con chacra agrícola para la niñez desamparada ${ }^{20}$.

Una vez superada la oposición, fue inaugurada auspiciosamente en febrero de 1905. La dirección fue confiada al exdirector de la institución homónima de Villa Urquiza, ya descripta. Entre sus objetivos estaba la capacitación agrícola y ganadera, pero además en manejo y montaje de maquinarias, industrias rurales, nociones de la economía rural y contabilidad agrícola (Vega, 1905, p. 98). La orientación de la enseñanza se 
reflejaba también en la composición de su personal: un director maestro de la Escuela de Aplicación anexa, un encargado de la contabilidad administrativa y agrícola, un maestro quesero, diez peones y una cocinera.

Contó con un predio de 150 hectáreas de labranza, una escuela primaria anexa y una "fábrica" de queso y manteca, un sector para mejoramiento de las razas vacunas ${ }^{21}$. Los requisitos de ingreso para los alumnos eran un mínimo de instrucción establecido por la ley de educación común en vigencia y la edad de 15 años. En 1906 contaba con catorce alumnos becados por la Dirección General de Enseñanza y uno costeado por la municipalidad. Sólo había un alumno pensionista. Aunque la prensa señalaba que la mayoría de los estudiantes provenían de familias acomodadas, los pedidos de beca para ingresar a cursar estudios allí ofrecían una perspectiva diferente, al estar justificados por la carencia de medios propios. Ese año la dirección quedó a cargo del agrónomo Florencio Álvarez, que con anterioridad cumplía tareas en la normal rural.

En 1907, tres de los alumnos que culminaron sus estudios solicitaron a la Dirección General de Enseñanza becas para cursar en la normal rural "Juan Bautista Alberdi”. El otorgamiento de este estipendio expresaba un reconocimiento a la aplicación y el comportamiento sostenido en la agropecuaria. Un elemento que aportó a la comprensión de la trayectoria posterior de estos jóvenes lo ilustraban los expedientes que registraban la deserción de tres alumnos por la falta de maestro de instrucción primaria, situación que era observada por padres y tutores como un obstáculo porque dificultaba el ingreso a la escuela normal rural "Juan Bautista Alberdi" o la continuidad de estudios.

En 1910 se concedieron becas para jóvenes de nacionalidad rusa y austriaca, radicados en las colonias cercanas a la institución.

\section{Escuela Agropecuaria "9 de julio" de Don Cristóbal Nogoyá: una escuela DENTRO DE UNA ESTANCIA}

A diferencia de las otras creaciones institucionales, la agropecuaria "9 de julio" ubicada en la colonia "Don Cristóbal” del departamento Nogoya ${ }^{22}$ se organizó a partir de la donación de 30 hectáreas realizada por un estanciero local, en 1903, y demandada por el vecindario local que exigió al inspector seccional de la Dirección General de Enseñanza:

\footnotetext{
...la inmediata instalación de una escuela de carácter agropecuario en la que se enseñaran en cuanto sea posible, la teoría y la práctica de las asignaturas que sirvan más directamente a las necesidades intelectuales y materiales de la vida en aquella apartada región. ${ }^{23}$
}

La respuesta fue rápida, de modo que ese mismo año se licitó la construcción del edificio, bajo la responsabilidad de inspección de la Sección de Agricultura de la Provincia. Esta obra se concluyó en junio de 1904 e inició sus actividades con un director interino para el cual fue nombrado Luis González y un peón. Las primeras acciones que se desarrollaron fueron cursos nocturnos para brindar un mínimo de instrucción en lectura, escritura, aritmética, agricultura y ganadería a los jóvenes hijos de colonos rusos y peones de las estancias circundantes que no podían asistir a las escuelas primarias comunes. De esta forma, ese año funcionó como un establecimiento de educación primaria con un número considerable de alumnos.

En 1905, el gobierno incluyó en su ley de presupuesto becas para diez alumnos internos, aún cuando las condiciones de alojamiento eran precarias, porque el director las consideraba imprescindibles para sostener el establecimiento: "porque aprovechando las horas libres de clases y estudios pueden dedicarse a todos los múltiples trabajos que ya va siendo imposible atender dado el mínimo de personal que dispongo" ${ }^{24}$.

El programa de estudio comprendía conocimientos de botánica, horticultura, agricultura general, agricultura especial, viticultura, arboricultura, industrias rurales, zootécnica, alimentación de ganado y veterinaria (Vega, 1905). Las prácticas agrícolas realizadas consistieron en la formación de almácigos y plantación de árboles frutales y florales, cultivo de moreras y cría de gusanos de seda, e incluso la reproducción de vacunos de raza, donados por vecinos de la colonia Don Cristóbal. 
En 1907 la dirección quedó a cargo del perito agrónomo Alfredo Felheisen como parte de los objetivos de la Dirección General de Enseñanza para asegurar que estas instituciones estuvieran dirigidas por este tipo de personal y en 1908 este puesto fue ocupado por ingeniero agrónomo Alfredo Elías.

En 1908 egresaron cinco jóvenes para los cuales se solicitó becas para cursar estudios en la normal rural "Juan Bautista Alberdi".

Los problemas que enfrentó este establecimiento fueron diversos: la ubicación dentro de una propiedad privada, sin camino público que condujera hasta ella; la distancia con respecto a las comunicaciones ferroviarias; y la falta de agua potable. Finalmente fue transformada en un establecimiento elemental con anexo agropecuario en 1912.

\section{LA escuela Agropecuaria “Tomás Espora” De Concordia y la Viticultura litoraL}

Este establecimiento fue creado, en 1904, en las proximidades de la ciudad de Concordia, cabecera del departamento ${ }^{25}$ del mismo nombre. Al igual que en otros departamentos linderos al río Uruguay, se implantaron viñedos en Concordia y se industrializó la uva, contando con una de las mayores producciones de la provincia ${ }^{26}$.

Concebida inicialmente como una normal regional para formar maestros de campaña, finalmente fue establecida como escuela agropecuaria e industrial ${ }^{27}$. Contaba con un campo de 50 hectáreas, de las cuales 30 fueron donadas por la Municipalidad de esa ciudad a la Dirección General de Enseñanza, 11 por unos reconocidos bodegueros locales y el resto por suscripción popular. Los argumentos de su fundación apelaban al pedido que los propietarios y arrendatarios locales hicieron para que se formaran personas capacitadas en forma teórica y práctica para el mejoramiento de las explotaciones agrícolas ${ }^{28}$. El objetivo era la formación de trabajadores idóneos para las explotaciones rurales en general, y en especial para la viticultura y vinicultura, arboricultura y horticultura. El plan de estudios inicialmente estableció una formación de cuatro años, con una organización simultánea de materias teóricas y prácticas donde articulaban saberes elementales y conocimientos agrícolas. Contaba con un campo experimental de 244 hectáreas en la colonia Yeruá, con una sección de vinificación y bodega, jardines de arboricultura, horticultura y de aclimatación, una estación meteorológica, una cabaña y una cremería y mantequería. A cargo de la tarea de inspección de terreno y dirección inicial de la escuela se nombró al ingeniero agrónomo sanjuanino Juan Zavalla.

La cantidad de alumnos que se admitía era "alrededor de veinte", pudiendo ser pensionistas, y la provincia sostenía quince becas para el internado. Entre las condiciones de admisión se requería tener una edad mínima de quince años, certificados de conducta y salud, conocimientos elementales de lectura, escritura y aritmética. Cuando los estudiantes concluían el cursado de sus estudios, obtenían un certificado de competencia agrícola.

De modo análogo a las otras instituciones, la carencia de insumos y el reclamo de incremento de personal era constante, presentando un panorama que se alejaba de las proyecciones iniciales y que era usado por sectores opositores al gobierno para cuestionar el sostenimiento de este tipo de establecimientos con fondos del erario provincial.

En 1908, la Ley de Presupuesto de la Provincia estableció una asignación para esta escuela que muestra la limitación del cuerpo docente, compuesto por director y profesor, un maestro elemental, secretario contador y un jefe de cultivo arboricultor. El personal se completaba con una cocinera, una lavandera, un celador ecónomo y dos peones para manutención del personal. Se continuaba con el sostenimiento de becas para quince alumnos ${ }^{29}$. Ese año Juan Zavalla renunció al cargo de director y fue reemplazado por el agrónomo Alberto Ferré, quien desempeñaba tareas en la institución homónima localizada en Villa Urquiza.

En 1909 de los cinco alumnos egresados, dos obtuvieron becas para ingresar a la escuela de Villa Urquiza y tres para la normal rural "Juan Bautista Alberdi”, concesión otorgada en forma de premio por el desempeño. 
En 1910 la designación de Eduardo Gorostiaga, exdirector de la agropecuaria de Villaguay, abrió nuevas expectativas en su organización, aunque serían efímeras porque el gobierno provincial acordó, a fines de 1911, su traspaso al Ministerio de Agricultura Nacional, convirtiéndose en una estación enológica.

\section{La escuela Normal e Industrial “Juan Bautista Alberdi” y la formación de MAESTROS NORMALES RURALES}

La preparación y ejercicio de la docencia de los maestros que se desempeñaban en el espacio rural fue una preocupación creciente del Estado y de la sociedad desde fines del siglo XIX. Este colectivo de educadores constituía un mosaico de realidades heterogéneas, caracterizadas por la ausencia de titulación y la carencia de una formación que permitiera ejercer con eficacia su labor en el medio rural y con una población escolar de origen extranjero. La expansión de la colonización agrícola y el aumento de la población acentuaron esas preocupaciones, especialmente cuando la escolarización se daba en instituciones particulares que sostenían las comunidades extranjeras recién llegadas al país.

La opción de cursar un año más de estudio en la escuela de Villa Urquiza para acceder al título de maestro rural funcionó por un tiempo y tuvo escaso impacto, ya que surgió en 1903 la alternativa de los cursos temporarios de verano para aspirantes al magisterio y maestros en ejercicio sin título. Esta medida paliativa tuvo una amplia recepción, ya sea por el carácter obligatorio de de los cursos temporarios o por la oportunidad que brindaban para la obtención de un título habilitante, manteniéndose durante el período estudiado pese a que habían sido proyectados con carácter de transitorios. Para esa fecha los datos estadísticos mostraban altos índices de personal no titulado: de los 850 maestros que se desempeñaban, tenían diploma 293 y carecían de él 557. Las escuelas fiscales fueron atendidas por 403 maestros de los cuales eran diplomados 201 y sin títulos $202^{30}$, localizados en su mayoría en el espacio rural.

La fundación de una escuela normal rural era un proyecto presente desde fines del siglo XIX, pero recién se concretó en 1903 cuando el gobierno provincial decretó la apertura de dos normales rurales e industriales en diferentes zonas de la provincia.

Por medio de la Ley $\mathrm{N}^{\circ} 1897$, se aprobó la adquisición de una propiedad que había pertenecido al exgobernador Ramón Febre, ubicada en el paraje de Tezanos Pinto en el departamento Paraná, con una extensión de 9.708 hectáreas que se destinarían a colonización mixta, fomento de la agricultura y la ganadería e instalación de una institución para formar maestros rurales. El casco de la estancia tenía las instalaciones necesarias para su organización, lindaba con una colonia agrícola, estaba cercana al paso del ferrocarril y no tan lejos de la capital provincial.

En marzo de 1904 se transfirieron a la Dirección General de Enseñanza de la Provincia esta estancia y una superficie de 400 hectáreas para que funcionara allí la Escuela Normal Agropecuaria e Industrial para varones. La misma inició sus actividades el 17 de julio de ese año con veinte alumnos, siete provenientes de la escuela de Villa Urquiza, siendo el total un número menor a los veintiocho proyectados inicialmente. La normativa de fundación de esta institución señalaba que su misión sería dar formación específica para los maestros de campaña y "suministrar los conocimientos de agricultura y ganadería suficientes para el manejo de una chacra en la explotación racional que concuerda con el medio regional de ubicación de cada escuela”. ${ }^{31}$

El énfasis estaba colocado en la formación general propia del normalismo, debiendo tener mayor preeminencia "sobre la agropecuaria e industrial, que debe ser secundaria (...) Si se acentúa mucho la tendencia industrial, pueden alejarse los futuros maestros, de la escuela, campo de sacrificios y escasos productos materiales" ${ }^{32}$. No obstante, las competencias agropecuarias serían un medio adecuado para difundir en la campaña el desarrollo de prácticas modernas "porque la escuela además de comunicar la instrucción común, se convertirá en un vasto campo de estudios teóricos y experimentales” ${ }^{33}$. 
El plan de estudios era de tres años, unos menos que las normales nacionales, divididos en semestres de invierno y verano. Comprendía cursos de pedagogía, castellano, aritmética, geometría y dibujo, historia y geografía, agregándose moral e instrucción cívica en el tercer año. En lo que refiere a la formación agropecuaria, las materias dictadas en los tres años eran: agricultura general, zootecnia general, ganadería, industrias rurales, agricultura especial, y ejercicios prácticos. En estas materias se incluían los contenidos agrícolas o ganaderos respectivos y se los complejizaba a medida que se avanzaba en el cursado del plan de estudio

Las condiciones de ingreso de los alumnos estipulaban que debían tener una edad entre los 16 y 21 años, con quinto grado de escuelas comunes aprobado; no debían padecer defectos físicos ni enfermedades, ni antecedentes de inmoralidad. Los alumnos podían ser becados provinciales o pensionados, en ambos casos previa constatación de su falta de recursos, quedando obligados una vez egresados a desempeñarse como maestros durante tres años en zonas rurales.

Se dictó un reglamento interno que fijaba las funciones del personal -director, vicedirector, jefe de cultivos, profesores, maestro de la escuela de aplicación, secretario, contador, capataces, carpinteros y empleados subalternos- y regulaba las actividades de los estudiantes. La dirección la desempeñaba un maestro o profesor normal, ${ }^{34}$ quedando la vicedirección y el cargo de jefe de cultivo bajo la responsabilidad de un ingeniero agrónomo.

En enero de 1908 egresaron los primeros diecisiete maestros normales rurales de la provincia, siendo destinados a los establecimientos elementales con anexos agropecuarios, que el gobierno había creado recientemente mediante la Ley de Presupuesto de 1908, y que completaban el panorama de creaciones institucionales que darían una orientación productiva a la educación común de la provincia.

El desarrollo de esta normal rural puede observarse a través del seguimiento de su peso en el presupuesto asignado al Consejo General de Educación. En el año 1908, se destacaba entre los demás establecimientos especiales porque insumía la mayor cantidad de recursos y tenía una organización interna más compleja, ya que contaba con seis profesores a cargo de la formación pedagógica y agropecuaria, personal técnico responsable y auxiliar en cada una de sus secciones -sección escuela de aplicación, cultivos, ganadería y lechería, talleres, economía y servicio interno- y becas y manutención para treinta y cinco alumnos.

\section{Escuela de Agricultura y Ganadería “Las Delicias": la presencia nacional en LA FORMACIÓN AGROPECUARIA PROVINCIAL}

La fundación del Ministerio de Agricultura de la Nación permitió en 1898 la organización de instituciones encargadas de la formación técnica agrícola en distintas zonas del país, conformando un subsistema propio de enseñanza (Gutiérrez, 2007) que se consolidó a partir de 1908, con nuevos reglamentos (Ascolani, 2011) y la organización de la Dirección General de Enseñanza Agrícola.

En la provincia de Entre Ríos se instaló una Escuela de Agricultura y Ganadería de esta dependencia mediante decreto del 3 mayo de $1900^{35}$.En esa misma norma que fundaba la institución se nombraba al ingeniero agrónomo Adolfo C. Tonnelier como director y Hugo Ferrando como ayudante secretario. Esta concreción se ubicaba en una zona de colonización de inmigrantes rusos -alemanes del Volga-e italianos, y ocupó 300 hectáreas con instalaciones de la estancia que había pertenecido al exgobernador Sabá Hernández (Reula, 1969, p. 205), del cual tomó el nombre y fue donada por la Provincia a la Nación, mediante la Ley N. ${ }^{\circ} 1758$, cuyos fundamentos señalaban la necesidad de instalar dicha escuela ${ }^{36}$. Una vez creada, la planta de personal quedó integrada con un director, un ayudante secretario, un carpintero horticultor, un encargado, una caballeriza-carrero, un carpintero y seis peones, aunque no se registraba información sobre presencia de alumnado. Se debían desarrollar cursos, concursos, conferencias y otras acciones que contribuyeran a la modernización de las prácticas agrícolas de los colonos que eran observadas críticamente, especialmente en el 
caso de las comunidades de rusos alemanes. Los cursos se desarrollarían durante dos años, siendo de carácter teórico-práctico, y permitirían la obtención de la certificación de capataz agrícola y ganadero. Con un año más de cursado el egresado podía especializarse en lechería.

Tres años después de su apertura, el ministro de Agricultura Nacional informaba que la escuela no había podido iniciar sus actividades de forma regular por diversos inconvenientes, entre ellos la carencia de agua potable ${ }^{37}$. A partir de septiembre de 1904 comenzó el primer semestre de actividades más orgánicas, con una asistencia de diez estudiantes que cursaron las siguientes materias: agricultura, aritmética, geografía, zootécnica, geometría, caligrafía, dictado, lectura, práctica, estudio. Para inscribirse como alumnosaprendices debían tener 15 años cumplidos y estar alfabetizados. A fines de ese año, la prensa local informaba que por razones económicas esta institución iba a ser suprimida, pero las gestiones del gobierno provincial evitaron su clausura ${ }^{38}$. Las dificultades que esta institución tenía para adaptarse al medio y progresar dieron lugar a que el ministro de Agricultura elaborara el plan de estudio para la escuela "Las Delicias" en conexión con las instituciones primarias y agropecuarias de Entre Ríos ${ }^{39}$, según lo difundió el director General de Enseñanza. Este establecimiento continuó en declive hasta que, en 1907, fue convertida en chacra experimental, en articulación con las modificaciones que se imprimían a la enseñanza agrícola dependiente del Ministerio de Agricultura Nacional ${ }^{40}$. A partir de esa fecha, la dirección estuvo a cargo del ingeniero agrónomo Ramón Corregidor.

En 1908, cuando se reorganizaron las escuelas dependientes del mencionado Ministerio, se dejaron sin efecto las reformas de 1907 que había convertido en chacras experimentales a varias de estas instituciones, aunque se reorganizó a "Las Delicias" como vivero regional hasta 1911, abasteciendo de plantas frutales, industriales ornamentales a la región y otras instituciones similares de la provincia. Ese año fue elevada a su rango definitivo, como establecimiento Práctico Regional de Agricultura.

\section{LAS ESCUELAS Agropecuarias RUMBO AL CENTENARio: MODERNIZACIÓN AGRÍCOLA Y LA NACIONALIZACIÓN DE LA POBLACIÓN}

A fines de 1908 se inició la reforma parcial de la Constitución Provincial mediante la Ley No 2175, que desembocaría en transformaciones en el sistema educativo -así como en el Superior Tribunal de Justicia y el Concejo Deliberante-. En la Convención Constituyente, la comisión redactora de las reformas se expidió sobre la educación común estableciendo que "comprenderá exclusivamente la instrucción primaria, será gratuita, obligatoria y de carácter esencialmente nacional" ${ }^{41}$. Esto implicaba la modificación de la Ley de Educación y una reducción en las funciones de la Dirección General de Enseñanza. La definición era clara, todos los esfuerzos de la administración educativa debían estar orientados a asegurar la escolarización de la población infantil, puesto que la provincia seguía teniendo altas tasas de analfabetismo.

Los promotores del cambio aseguraban que no implicaría una desaparición de las escuelas especiales, “pero que ellas no deben afectar ni disminuir la renta destinada a la educación común”. ${ }^{42}$ En verdad, el sostenimiento de este tipo de instituciones despertaba críticas -a las que se enfrentaba ya desde 1906 el director General de Enseñanza, Manuel Antequeda- ya que consumían recursos en desmedro de la instrucción primaria, que era un factor esencial para la transformación cultural de los futuros electores y para la nacionalización de la infancia de origen inmigrante que poblaba gran parte de la provincia ${ }^{43}$. Ese año, de especial efervescencia del nacionalismo en los ámbitos escolares, había resonado en la prensa un conflicto entre el inspector nacional de Escuelas de Provincia del Consejo Nacional de Educación Ernesto Bavio y el director General de Enseñanza en torno a los establecimientos particulares de las colonias ruso-alemanas e israelitas, quedando en entredicho la eficacia del gobierno provincial para atender la educación elemental y asimilar el aluvión inmigratorio, especialmente de las colectividades más autónomas como los alemanes del Volga y los rusos judíos (Carli, 1993; López, 1999). 
De tal modo, si bien la enseñanza especial quedaba reconocida por su potencial importancia para mejorar la producción agropecuaria, el costo de su sostenimiento ponía en riesgo su continuidad. En consecuencia, se proyectaba la reducción de este tipo de establecimientos, con excepción de la Normal e Industrial “Juan Bautista Alberdi” porque se consideró que había cumplido los objetivos previstos en su creación y era necesaria para articular los propósitos de nacionalización de la infancia y de orientación productiva del currículo de la educación primaria rural, incluso con la paralela asimilación de los jóvenes inmigrantes con vocación docente:

La forma más práctica de realizar esta aspiración del gobierno es formándoles el maestro que surja del seno mismo de las colonias y vaya a ejercer sus funciones docentes con alma e ideales argentinos y con preparación suficiente para desenvolver eficazmente su acción en el medio que va actuar... ${ }^{44}$

A partir de esta fecha, estos objetivos se plasmaron en el otorgamiento de un número fijo de becas para alumnos provenientes de las colonias rusas alemanas de Diamante y las israelitas ubicadas en los departamentos de Villaguay, Colón y Concepción del Uruguay.

En otras palabras, los maestros normales rurales fueron uno de los agentes en que confió el Estado provincial para concretar la articulación de la instrucción elemental, la nacionalización de la población inmigrante y la modernización del espacio rural de la provincia.

\section{Conclusiones}

Las instituciones de enseñanza con finalidades de capacitación agropecuaria y tendientes a cierta regionalización productiva creadas en la provincia de Entre Ríos fueron iniciativa de sus gobiernos, especialmente el de Enrique Carbó. Lograron materializarse gracias a la Constitución provincial de 1903, que les brindó un encuadre legal para su concreción y la asignación de recursos propios en el presupuesto de educación. Es perceptible que los sucesivos gobiernos de la Provincia mantuvieron la voluntad de contribuir a la superación de la crisis productiva facilitando la colonización agrícola. La organización de un número importante de escuelas agropecuarias indicaba que esta podía ser una vía que contribuyera a la modernización de las técnicas de producción y administración de las explotaciones mediante la capacitación de personal idóneo para el desarrollo productivo de la provincia. Sin contar con pruebas contundentes sobre la existencia de un proyecto orgánico que articule a dichas escuelas, resulta arriesgado pensar en la posibilidad de que se estuviera construyendo un subsistema provincial de educación especial. Por el contrario, la heterogeneidad en los orígenes, organización interna, currículo y personal de estas instituciones indica que se habría tratado de experiencias singulares, con un desarrollo cambiante según las circunstancias individuales. Esta mirada de conjunto no desconoce la identificación de aspectos comunes entre estas instituciones. En relación a esto se puede observar el sostenimiento de becas por parte del Estado provincial para jóvenes que acreditaban no contar con recursos para su manutención; estos jóvenes eran de procedencia rural, fundamentalmente, aunque también se registró un número menor de pedidos provenientes del ámbito urbano. Con respecto a este último punto, garantizar la presencia de jóvenes de la zona de colonias alemanas e israelitas fue un objetivo explicito a fines del período estudiado. Otro rasgo común era la ubicación de estos establecimientos en áreas de colonias agrícolas con población inmigrante, aspecto que era ampliamente promocionado para el mejoramiento de prácticas agrícolas.

Las fuentes a las que se accedió permitieron observar que era recurrente que al finalizar la formación en las escuelas agropecuarias, los egresados solicitaran becas para continuar sus estudios en la normal rural "Juan Bautista Alberdi”. Por este motivo, resulta difícil evaluar el impacto que estas instituciones pueden haber tenido en la preparación de personal para el trabajo en el espacio rural durante este período.

La extensión de cada unidad productiva en la que se ubicaban estos establecimientos también era un punto en común. Dicha situación permitía el desarrollo de actividades de experimentación agrícola y ganadera, así 
como también la obtención de materias primas que eran vendidas o distribuidas entre otras instituciones de la provincia. La alternancia y circulación de personal directivo entre los establecimientos provinciales fue otro punto de convergencia, notándose un esfuerzo importante por parte de los ámbitos de dirección del sistema educativo provincial para dotar de personal técnico específico a las mismas.

Las insuficiencias de infraestructura, de insumos, los cambios de dependencia estatal, las limitaciones de la matrícula -que fue sostenida con becas financiadas- y la dificultad para instalar el régimen de internado fueron factores adversos, a los que se sumó la oposición de los sectores de opinión que veían a estas instituciones como un desvío de fondos que necesitaba la educación primaria.

Cabe destacar que la presencia del Ministerio de Agricultura Nacional estuvo limitada en la educación de esta provincia -durante este período- a la organización de una institución de Agricultura y Ganadería, "Las Delicias", de frágil y discontinuo funcionamiento en este momento inicial, hasta que fuera reabierta y reorganizada en 1911, bajo la categoría de Escuela Práctica de Agricultura y Ganadería.

La reforma constitucional provincial de 1909 abrió un período de reducción de los establecimientos de educación de jurisdicción provincial y de mayor dependencia con respecto a las iniciativas y aportes del gobierno nacional. Como excepción a la regla, la Escuela normal rural industrial "Juan Bautista Alberdi" fue una institución que se consolidó progresivamente. Su éxito se puede atribuir a que logró unificar objetivos pedagógicos y de enseñanza agropecuaria a través de su diseño curricular, que incorporaba de modo innovador conocimientos técnicos agropecuarios, sin dejar de capitalizar el prestigio y el arraigo que ya tenían las escuelas normales.

\section{BiBLIOGRAFÍA}

Ascolani, A. (2007). Las Escuelas Normales Rurales en Argentina. Una transición entre las aspiraciones de la cultura letrada el imaginario de cambio socioeconómico agrario (1900-1946). En Corrêa Werle (comp.), Educação Rural em Perspectiva Internacional. Instituiçôes, práticas eformação do professor (pp.373-424). Ijuí, Brasil: Editora UNIJUI.

Ascolani, A. (2011). Los agricultores y la educación para la modernización e integración social, durante el apogeo y crisis de la Argentina agroexportadora (1899-1936). En Civera, A., Alfonseca, J. y Escalante, C. (coord.), Campesinos y escolares: la construcción de la escuela en el campo latinoamericano (siglos XIX y XX) (pp. 349-392). México: Porrúa-El Colegio Mexiquense.

Ascolani, A (2012). La escuela primaria rural en Argentina. Expansión, orientaciones y dificultades (1916-1932). Teias, 14(28), 309-324. Recuperado de http://www.e-publicacoes.uerj.br/index.php/revistateias/article/view/ 24245

Ascolani, A (2014). El agrónomo Silvio Spangenberg y la consolidación de la Escuela de Agricultura de Casilda (1900-1928). HISTEDBR on line, 14(60), 3-20. Recuperado de https://periodicos.sbu.unicamp.br/ojs/index. $\mathrm{php} / \mathrm{histedbr/article/view/8640545}$

Ascolani, A (2015). Ruralidad, analfabetismo y trabajo en la Argentina. Proyectos y acciones del Consejo Nacional de Educación (1930-1940). Cadernos de História da Educação 14(3), 853-877. Recuperado en http://www.seer.uf u.br/index.php/che/article/view/33141

Ascolani, A(2017). Concepciones reformistas en torno a las funciones de la Educación Primaria Rural Argentina (1930-1960). Dialogia, revista de politica y gestión educativa, 25, 43-68. Recuperado de http://www4.uninove. br/ojs/index.php/dialogia/article/view/6997

Avni, H. (2005). Argentina y las migraciones judías. De la Inquisición al Holocausto y después. Buenos Aires: Editorial Milá.

Barsky, O. y Gelman, J. (2005). Historia Del agro argentino. Desde La conquista hasta fines del siglo XX. Buenos Aires: Mondadori.

Bosch, B. (1991). Historia de Entre Ríos 1520-1990. Buenos Aires: Plus Ultra. 
Brumat, M. R. (2010). Formación de maestros normalistas rurales en Argentina, En Flávia Obino Corrêa Werle (Organizadora), Educação Rural: práticas civilizatórias e institucionalização da formação de profesores. Brasilia: PP Editorial OIKOS, Liber Livro.

Carli, S. (1993). Modernidad, diversidad cultural y democracia en la historia educativa entrerriana (1883-1930). En Puiggros, A. (Dir.), La educación en las provincias y territorios nacionales (1885-1945). Historia de la educación en la Argentina IV, (pp185-237). Buenos Aires: Galerna.

Djenderedjian, J. (2008). Historia del capitalismo agrario pampeano. La agricultura pampeana en la primera mitad del siglo XIX. Buenos Aires: Siglo XXI

Djenderedjian, J. (2008). La colonización agrícola en Argentina, 1850-1900: problemas y desafíos de un complejo proceso de cambio productivo en Santa Fe y Entre Ríos. América Latina en la Historia Económica. Revista de Investigación, 30, 128-157. Recuperado en http://alhe.mora.edu.mx/index.php/ALHE/issue/view/44

Djenderedjian, J. y Martirén, J. L. (2012). La distribución de la riqueza rural entre tradición modernidad. Los casos de la Colonia Esperanza y el distrito de Paraná durante la década de 1860. Población \& Sociedad [en línea], 19(2), 125-154. Recuperado en http://www.poblacionysociedad.org.ar/index.php?go=23

Dussel, I. (1997). Currículo, Humanismo y democracia en la enseñanza media, 1863-1920. Buenos Aires: FLACSO/ UBA.

Gallo, E. (1984). La pampa gringa. Buenos Aires: Sudamericana.

Gutiérrez, T. (2005) La educación del colono en épocas de conflicto: entre la defensa de sus intereses y el control social, 1910-1922. En Revista del EIAL (Estudios interdisciplinarios de América Latina), Tel Aviv,primer semestre V 16, No 2,julio-dic de 2005, p 85-110. Recuperado en http://www7.tau.ac.il/ojs/index.php/eial/article/viewFil $\mathrm{e} / 345 / 314$

Gutiérrez, T. (2007a). Educación, agro y sociedad. Politicas educativas agrarias en la región pampeana 1897-1955. Buenos Aires: Editorial Universidad Nacional de Quilmes.

Gutiérrez, T. (2007b). Políticas de orientación agrícola y pedagogía normalista. Entre Ríos, Argentina, 1900-1920. Perfiles Educativos, 29(117), 85-110. Universidad Nacional autónoma de México. Recuperado en http://www .redalyc.org/articulo.oa?id $=13211705$

Hora, R. (2010). Historia económica de la Argentina en el siglo XIX. Buenos Aires: Fondo de Cultura Económica.

INTA (2008). Zonas Agro Económicas Homogéneas Entre Ríos Descripción ambiental, socioeconómica y productiva. Recuperado de https://inta.gob.ar/sites/default/files/script-tmp-inta_zonas_agroeconmicas_homogneas_entr e_ros.pdf

Martirén, J. L. (2016). La transformación farmer. Colonización agricola y crecimiento económico en la provincia de Santa Fe durante la segunda mitad del siglo XIX. Buenos Aires: Prometeo.

Mayer, M. S. (2014). Educación rural, inmigración y relaciones sociales. Dos procesos de colonización agricola en la provincia de Entre Rios. Buenos Aires: la Colmena.

Moyano, D. (2011).La Escuela de Arboricultura y Sacarotecnia de Tucumán y su papel en el desarrollo agroindustrial de la provincia, 1880-1920. Travesia, 13, 229-246. Recuperado en http://www.travesia-unt.org.ar/cuerponum eros.php?nlibro $=13$

López, M. P. (1999). La educación de rusos judíos y alemanes del Volga en Entre Ríos. Conflictos político-pedagógicos (1880-1910). En Ascolani, A. (comp.), La educación en Argentina. Estudios de historia (pp 71-83). Rosario: Ediciones del Arca.

Reula, F. (1969). Historia de Entre Ríos. Santa Fe: Castellví 326.

Rodríguez Vázquez, F. (2011). La educación agrícola en una economía regional: el aporte de la Escuela Nacional de Vitivinicultura en Mendoza y San Juan (1900-1920). Prohistoria. Versión On-line, 16. Recuperado de http://w ww.scielo.org.ar/scielo.php?script=sci_arttext\&pid=S185195042011000200002

Rodríguez Vázquez, F. (2013). Educación y viticultura. Formación de recursos humanos y generación de conocimientos técnicos en Mendoza (1890-1920). Rosario: Prohistoria ediciones. 
Rodríguez Vázquez, F. (2014). Educación agrícola, enólogos y tecnologías para una vitivinicultura "de calidad", Mendoza, 1890-1930. Mundo Agrario, 15(29). Recuperado de http://www.mundoagrario.unlp.edu.ar/article/ view/2321

Plencovich, C., Costantini, A. y Bocchicchio, A. M. (2009). Educación agropecuaria en la Argentina. Génesis y estructura. Buenos Aires: CICCUS.

Popp, V. P. y Dening, N., (1977). Los Alemanes del Volga. Buenos Aires: Gráfica Santo Domingo.

Schmit, R. (2004). Ruina y resurrección en tiempos de guerra: sociedad, economia y poder en el Oriente entrerriano posrevolucionario, 1810-1852. Buenos Aires: Prometeo Libros.

Tedesco, J. C. (1986). Educación y sociedad en la Argentina (1880-1945). Buenos Aires: Ediciones Sol.

\section{Notas}

1 Este artículo recupera los aspectos centrales de la ponencia "Escuelas agropecuarias y maestros normales rurales en Entre Ríos: entre la modernización agrícola y la integración social (1900-1910)" presentada en las XIII Jornadas Nacionales y VInternacionales de Investigación y Debate. Sujetos Sociales y Territorios Agrarios Latinoamericanos. Siglos XX y XXI. Universidad Nacional de Quilmes, 27 al 29 de julio 2016.

2 En este artículo no se trabajó sobre las iniciativas de índole privada desenvueltas en este período, sin desconocer por eso la relevancia de las mismas. Con esto se está aludiendo al colegio agrícola de la orden benedictina instalada en el ejido de la ciudad de Victoria en el año 1899.

3 La primera colonia agrícola militar fue "Las Conchas", fundada en 1853 y poblada con inmigrantes alemanes, luego reorganizada bajo la denominación de Villa Urquiza. Le siguió la creación de la colonia "San José”, en 1857, de iniciativa privada. Ambas fueron emprendimientos impulsados por el gobernador Justo José de Urquiza.

4 Provincia de Entre Ríos, Memoria presentada a la Honorable Legislatura de Entre Rios por el Ministro de Gobierno Dr. Salvador Macia. Paraná, Tipografía, litografía y encuadernación, 1892.

5 Departamento General de Estadística de la provincia de Entre Ríos Anuario correspondiente al año 1896. Paraná: Tipografía y Encuadernación El Paraná de Joaquín Sors 1897.

6 Desde la segunda mitad del siglo XIX, en la provincia habían predominado dos formas de colonización. Por una lado la colonización oficial a cargo del Estado, que permitía la posesión de tierras por parte del colono; la otra, bajo responsabilidad de empresarios privados que posibilitaban el arrendamiento o la aparcería, con consecuencias negativas para un asentamiento definitivo y en menor medida las iniciativas mixtas entre Estado y privados. Aunque la colonización con tierras fiscales era la más beneficiosa, su empuje se había detenido en 1885, cuando se agotaron las tierras fiscales necesarias para este proceso. En la gobernación de Enrique Carbó (1903-1907) se dictaron nuevas leyes de organización de colonias: "Lucas Gonzales", "Algarrobitos", "Ramírez", Camps", "Delicias" y "Ensayo".

7 En el cargo de director General de Enseñanza se nombró al profesor Normal Manuel Pacífico Antequeda (1860-1920) quien se desempeñó de forma ininterrumpida en el mismo durante 1903 y 1914. Este funcionario nació en Mendoza y se trasladó a Entre Ríos donde se graduó en 1878 como maestro normal y al año siguiente obtuvo el título de profesor Normal. Se desempeñó en Buenos Aires, Mendoza y San Juan, en esta última provincia ocupó cargos de Intendente Municipal, Ministro de Gobierno e Instrucción Pública, Vocal del Consejo de Educación, diputado y senador. En 1903 fue convocado para ocupar la Dirección General de Escuelas en Entre Ríos durante la gobernación de Enrique Carbó.

8 Dirección General de Enseñanza, Boletín de Educación. Año XV, № 167 a 170, enero a abril de 1906. Paraná, Entre Ríos p. 15.

9 Consejo General de Educación, Boletín de Educación, Año XXI, $3^{\circ}$ época. № 238 a 243, enero a junio de 1912. Paraná Entre Ríos p 5.

10 Archivo General de la provincia de Entre Ríos. Fondo Educación. Serie XI. Paraná, Caja 6 No orden 10, 1896.

11 Provincia de Entre Ríos, Recopilación de leyes, decretos y acuerdos de la provincia de Entre Ríos. Año 1898. Tomo XXXVIII. Paraná, imprenta Coronado, p 63-64.

12 La localidad de Villa Urquiza se sitúa en el departamento Paraná, a $20 \mathrm{~km}$ de la ciudad homónima. Es un área que se caracteriza por ambientes agroecológicos similares a la región pampeana. Esta zona es una de las más diversificadas de la provincia porque el uso del suelo se distribuye entre varias actividades, sobresaliendo las producciones relacionadas con la agricultura y la ganadería de carne y leche.

13 Las referencias localizadas sobre este ingeniero agrónomo son fragmentarias. Sobre su trayectoria en la burocracia educativa provincial se registró su desempeñó como director de la Escuela de Agricultura, Ganadería e Industrias Derivadas entre 1896 y 1905. Ese año fue nombrado director organizador de la escuela agropecuaria "Justo José de Urquiza" en Villaguay. En 1906 fue convocado para ejercer el cargo de director de la Estación Experimental dependiente 
de la Sección de Agricultura del Ministerio de Gobierno de la provincia de Entre Ríos. En 1909 la prensa local aludía a las actividades que este funcionario desempeñaba como comisionado nacional en las provincias de Entre Ríos, Corrientes y Chaco para la difusión de la Exposición Internacional de Agricultura de 1910.

14 AGER. Fondo Educación. Serie XI. Paraná, Caja 14 No orden 19, 1901.

15 Provincia de Entre Ríos, Recopilación de leyes, decretos y acuerdos de la provincia de Entre Ríos. Año 1901. Tomo XLI. Paraná, imprenta Zavalla. p 378-379.

16 Escuelas de agricultura (31 de julio de 1903). Periódico, La Libertad. Entre Ríos.

17 Provincia de Entre Ríos, Memoria presentada a la honorable legislatura de la provincia por el ministro de gobierno Ing. Alberto Mendez Casariego Tomo I, 1903-1904. Buenos Aires, Compañía Sud Americana de Billetes de Banco, 1904.p. 205.

18 El departamento Villaguay se ubica en el centro de la provincia de Entre Ríos. El relieve de la zona está caracterizado por su topografía suavemente ondulada a plana. Los suelos tienen limitaciones severas que restringen la elección de cultivos, requieren un manejo muy cuidadoso o demandan el uso prácticas de conservación. Pueden ser utilizados para cultivos, pasturas o como campos naturales de pastoreo, predominando la actividad ganadera.

19 Provincia de Entre Ríos Cámara de Senadores. Diario de sesiones de 1904. Paraná, tipografía, litografía y papelería El Paraná, 1909. p 76-77.

20 La chacra agrícola de menores. Por la niñez desamparada. Quemamos el último cartucho (12 de diciembre de 1904). Periódico El Tribuno, Entre Ríos.

21 Servicio de Haras en la Escuela Agropecuaria “Urquiza” (6 de noviembre de 1905). Periódico El Tribuno, Entre Ríos.

22 El departamento Nogoya se ubica en el centro-suroeste de la provincia de Entre Ríos y presenta un ambiente de transición entre los tipos pampeanos del suroeste y los suelos típicos del centro de la provincia. El uso del suelo se emplea para actividades ganaderas y agrícolas, siendo una zona tradicionalmente tambera.

23 AGER. Fondo Educación. Serie IX. Nogoya, Caja 2 orden No 7, 1904.

24 AGER, Fondo Educación, Serie No IX, Nogoya. Caja 2 orden No 5, 1905.

25 El departamento Concordia se ubica en la zona noreste de la Provincia. Estos suelos se encuentran entre los más aptos de la provincia para la implantación de citrus. Las principales producciones están relacionadas con la citricultura, la forestación y la ganadería de carne y ovinos.

26 Ministerio de Agricultura de la Nación. Memoria presentada al Honorable Congreso enero de 1899-octubre de 1900. Buenos Aires: Imprenta de M Biedma e hijos. p. 253.

27 AGER Fondo Educación. Serie II. Concordia. Caja 4, No orden 1.

28 AGER. Fondo Educación. Serie II. Concordia. Caja 4, S/No orden

29 Provincia de Entre Ríos. Ley de Presupuesto General de la Administración para el ejercicio de 1908. Paraná, Tipografía, liberaría y encuadernación Coronado, 1907p. 129.

30 Provincia de Entre Ríos, Memoria presentada a la honorable legislatura por Dr. Mariano E. López. Ministro de Hacienda, Justica e Instrucción pública de la provincia año 1904. Paraná Tipografía Gutenberg, 1904. p. 109.

31 Provincia de Entre Ríos, Recopilación de Legislación de Educación Pública 1904 (s/l, s/n).p.133.

32 AGER, Fondo Educación Serie Escuela "Juan Bautista Alberdi Caja 1, 1905

33 Dirección General de Enseñanza, Boletín de Educación. Año XVI, No 182 a 185, mayo a agosto de 1907, Paraná Entre Ríos. p. 76

34 Durante los primeros años de funcionamiento el personal directivo de la escuela se caracterizó por la inestabilidad, lo cual era observado de forma negativa por diferentes sectores de la opinión pública. El primer director fue el profesor normal Ramón Medrano (1904) y en la vice dirección el ingeniero agrónomo Amadeo Contegrand. A inicios de 1906 asumió transitoriamente el cargo directivo el ingeniero agrónomo nacional Francisco Fernández y la vicedirección el maestro normal Antonio Rodríguez. Ese mismo año el primer cargo fue ocupado por el Dr. Luis Goncebatt, graduado de la Universidad del Estado de Ohio EEUU en agronomía y veterinaria. En febrero de 1907 la dirección de la escuela quedó bajo la responsabilidad del profesor Manuel Martínez y la vicedirección de Guillermo Spark. hasta el nombramiento del profesor normal e ingeniero agrónomo Modesto Quiroga. Este profesional también se había obtenido su titulación en la Universidad de Ohio y era maestro de ciencias agrícolas por la universidad de Cornell. En 1908 fueron designados en el puesto los profesores Felipe Gardell, Amadeo Austcher y Gervasio Barzola. Luego de la renuncia de este último, se designó a Soriano Romero en 1909.

35 Ministerio de Agricultura de la Nación. Memoria presentada al Honorable Congreso enero de 1899-octubre de 1900. Buenos Aires: Imprenta de M Biedma e hijos.

36 Provincia de Entre Ríos, Recopilación de leyes, decretos y acuerdos de la provincia de Entre Ríos. Año 1900. Tomo 40. Paraná, imprenta Zavalla. 19æ?pp. 397-399.

37 Ministerio de Agricultura de la Nación. Memoria presentada al Honorable Congreso por el Ministro de Agricultura Dr. Wenceslao Escalante 1902-1903. Imprenta de M Biedma e hijos. p 95.

38 La escuela de Las Delicias (12 de diciembre de 1904). Periódico El Tribuno, Entre Ríos. 
Mundo Agrario, diciembre 2018, vol. 19, n 42, e093. ISSN 1515-5994

39 Por las Escuelas agropecuarias (20 de septiembre de 1905). Periódico El Tribuno, Entre Ríos.

40 Entre Ríos, Escuela agrotécnica “Las Delicias”, libro copiador 1907.

41 Provincia de Entre Ríos. Convención Constituyente 1908-1909, Actas. Paraná, 1908-1909.Actas.

42 Notas del día. La carta del Doctor Macia. Nuestras conclusiones (29 de enero de 1909). Periódico El Tribuno, Entre Ríos.

43 Dirección General de Enseñanza, Boletín de Educación. Año 1909, No 209 a 213, agosto a diciembre de 1909. Paraná, Entre Ríos. p. 5.

44 Dirección General de Enseñanza, Boletín de Educación. Año 1909, No 205 a 208, abril a julio de 1909. Paraná, Entre Ríos p. 2. 